\section{Physicochemical Properties and Dentin Bond Strength of a Tricalcium Silicate-Based Retrograde Material}

Camila de Paula Telles Pires Lucas ${ }^{1}$, Raqueli Viapiana', Roberta BossoMartelo ${ }^{1}$, Juliane Maria Guerreiro-Tanomaru', Josette Camilleri², Mário Tanomaru-Filho ${ }^{1}$
'Department of Restorative Dentistry, Araraquara Dental School, UNESP - Universidade Estadual Paulista, Araraquara, SP, Brazil ${ }^{2}$ Department of Restorative Dentistry, Faculty of Dental Surgery, University of Malta, Malta

Correspondence: Mário TanomaruFilho, Rua Humaitá, 1680, Centro, 14.801-903 Araraquara, SP, Brasil. Tel: +55-16-3301-6391. e-mail: tanomaru@uol.com.br

\begin{abstract}
The aim of this study was to evaluate the physicochemical properties and the apical dentin bond strength of the tricalcium silicate-based Biodentine in comparison to white MTA and zinc oxide eugenol-based cement (ZOE). Setting time and radiopacity were evaluated according to ISO 6876:2012 specification. Final setting time, compressive strength and $\mathrm{pH}$ were also assessed. Material's bond strength to the apical root canal dentin was measured by the push-out assay. Data were analyzed by ANOVA and TukeyKrammer post-hoc test. Biodentine presented the shortest initial (16.2 $\pm 1.48 \mathrm{~min})$ and final setting time $(35.4 \pm 5.55 \mathrm{~min})$. Radiopacity of Biodentine $(2.79 \pm 0.27 \mathrm{mmAl})$ does not agree with ISO 6876:2012 specifications. On the other hand, Biodentine showed higher compressive strength after 21 days $(37.22 \pm 5.27 \mathrm{MPa})$ and higher dentin bond strength $(11.2 \pm 2.16 \mathrm{MPa})$ in comparison to white MTA $(27.68 \pm 3.56 \mathrm{MPa}$ for compressive strength and $2.98 \pm 0.64 \mathrm{MPa}$ for bond strength) $(\mathrm{p}<0.05)$. Both MTA and Biodentine produced an alkaline environment (approximately $\mathrm{pH} 10)(\mathrm{p}>0.05)$ compared to $\mathrm{ZOE}(\mathrm{pH} 7)$. It may be concluded that Biodentine exhibited faster setting, higher long-term compressive strength and bond strength to the apical dentin than MTA and ZOE.
\end{abstract}

Key Words: mineral trioxide aggregate, tricalcium silicate, dentin bond strength, physicochemical properties

\section{Introduction}

Mineral trioxide aggregate (MTA) is a tricalcium silicate and presents proper biological properties and capacity to induce mineral tissue deposition (1). Newer materials, based on tricalcium silicate do not include any impurities as those based on Portland cement (2). Biodentine ${ }^{\mathrm{TM}}$ (Septodont Ltd., Saint Maur des Fosses, France) consists of a powder-liquid mixing system. The powder consists of tricalcium silicate, calcium carbonate, zirconium oxide and iron oxide and has greater amount of tricalcium silicate than MTA, while the liquid (vehicle) is consists in an aqueous solution of water-soluble polymer (water reducing agent) with calcium chloride (accelerator) (3).

According to the manufacturer, Biodentine is indicated to replace enamel temporarily, as permanent dentin restoration in the crown and in deep cervical or radicular carious lesion in the root (4). This material was also used as pulp capping material and as reparative material in perforations, internal/external resorptions, apexifications and retrograde fillings (5). Thus, this material exhibited adequate resistance to be placed in regions where mechanical strength is required, like underneath final restorative procedures (6).

Studies report that Biodentine exhibited acceptable radiopacity values, high washout resistance, lower fluid uptake and sorption, lower setting time and superior mechanical properties in comparison to other tricalcium silicate-based cements (7). It also had shown greater resistance to dislodgment in comparison to MTA when used as furcation repair material (8). However, there is a lack of information on the properties and interaction of this material with dental structures when used as retrograde filling material.

The aim of this study was to assess the physicochemical, mechanical properties and material bond strength to apical dentin of Biodentine, MTA Angelus and zinc oxide eugenol cement (ZOE).

\section{Material and Methods}

This research was approved by the Research Ethics Committee of the Araraquara Dental School ( UNESP, Araraquara, SP, Brazil) (process number 87/11).

The following available endodontic cements were included in this study: White MTA (Angelus, Londrina, PR, Brazil); Zinc oxide eugenol-based cement (ZOE; S.S. White Art. Dent. Ltda., Rio de Janeiro, RJ, Brazil); Biodentine (Septodont, Saint Maur des Fosses, France).

The materials were mixed according to the manufacturers' instructions. White MTA was mixed at 3:1 ratio in weight (powder-to-liquid). ZOE cement was mixed at 5:1 ratio (1 
g powder/0.2 mL liquid). To mix Biodentine, five drops of the liquid supplied by the manufacturer were placed in the capsule with powder and the set was ground for $30 \mathrm{~s}$ using a mixing device (SDI Ultramat 2, Bayswater, Victoria, Australia).

\section{Setting Time}

Stainless steel ring mould (10 $\mathrm{mm}$ inner diameter and $2 \mathrm{~mm}$ high) were placed over a glass slab, filled with fresh cement mixtures $(n=5)$. Initial setting time was obtained using a Gilmore needle indenter with a head weight of $100 \pm 0.5 \mathrm{~g}$ and $2.0 \pm 0.1 \mathrm{~mm}$ thick lowered vertically on the surface of the cement as recommended by the ISO 6876:2012 standard (9). In addition, a Gilmore needle indenter with a head weight of $456 \pm 0.5 \mathrm{~g}$ and $1.0 \pm 0.1 \mathrm{~mm}$ thick was also used in order to establish the final setting time of the cements. During the tests, the samples were maintained in an incubator at $37{ }^{\circ} \mathrm{C}$ and $95 \%$ humidity. The mean time elapsed from the end of mixing until no more indentations could be produced by both Gilmore needles on specimens' surface was established as the cement's setting time.

\section{Radiopacity}

Circular moulds were used to produce five samples of each material with $10 \mathrm{~mm}$ diameter and $1 \mathrm{~mm}$ thick, according to ISO 6876:2012 specification (9). Fresh mixed cements were inserted into the moulds and stored at $37^{\circ} \mathrm{C}$ and $95 \%$ humidity for $48 \mathrm{~h}$. Then, the samples were removed from the moulds and placed over an occlusal radiographic film (Insight - Kodak Co., Rochester, NY, USA) along with an aluminium step-wedge. The assembly was radiographed using an X-ray unit (General Electric Company, Milwaukee, WI, EUA) operating at $70 \mathrm{kV}, 7 \mathrm{~mA}$, with 0.32 pulses per $\mathrm{s}$, and at $33 \mathrm{~cm}$ film-focus distance. The exposed films were processed in an automatic film processor ( $\mathrm{A} / \mathrm{T} 2000^{\circledR} \mathrm{XR}$, Air Techniques Inc., Hicksville, NY, USA), digitized and evaluated in the Image J Launcher software for Windows, in order to determine the radiopacity equivalence of each cement with respect to the aluminium step-wedge ( $\mathrm{mm} \mathrm{Al)}$.

\section{Compressive Strength}

The compressive strength of the materials was evaluated according to ISO 6876:2012 specifications (9). Six samples $12 \mathrm{~mm}$ high and a $6 \mathrm{~mm}$ diameter were produced by filling metallic moulds with the materials and incubating them at $37^{\circ} \mathrm{C}$ and $95 \%$ relative humidity for 3 times the material's setting time. After, the samples were removed from the moulds and the flat surfaces of the samples were polished with a wet 600-grit sandpaper to standardize sample height (12 mm). The specimens' height was measured by a digital caliper (Mitutoyo, Suzano, SP, Brazil). Samples were incubated (at $37{ }^{\circ} \mathrm{C}$ and $95 \%$ humidity) for $24 \mathrm{~h}$ and 21 days, and then placed between the platens of a compressive strength test machine (Emic DL 2000, Emic) with a load cell of $5 \mathrm{kN}$ and $0.5 \mathrm{~mm} / \mathrm{min}$ cross head speed. The maximum stress sustained by the cements was calculated considering the maximum load with respect to sample diameter and was expressed in $\mathrm{MPa}\left(\mathrm{N} / \mathrm{mm}^{2}\right)$.

\section{$p H$}

Ten polyethylene tubes $(10 \mathrm{~mm}$ long and $1 \mathrm{~mm}$ inner diameter) were filled with freshly mixed cements and immersed in distilled water $(10 \mathrm{~mL})$. Samples were stored at $37^{\circ} \mathrm{C}$ throughout the experiment and $\mathrm{pH}$ readings were performed using a calibrated digital pHmeter (Digimed, Santo Amaro, SP, Brazil) after 3, 12, $24 \mathrm{~h}$ and 7, 14 and 21 days after mixing. At each period of analysis, the elution was collected for testing and replaced by fresh distilled water. Ten millilitres of distilled water was used as negative control ( $\mathrm{pH}=7$, approximately).

\section{Dentin Bond Strength}

The apical portion of single-rooted teeth extracted for periodontal reasons with complete root formation, no accentuated root curvature or calcifications were included in the study. Sample size was calculated based on effect size $=0.94$, power $b=95 \%$ and $\alpha=5 \%$ input into an F-test family for one-way analysis (G*Power 3.1 for Windows) and a total of 21 samples was required to perform this study. The roots were sectioned $8 \mathrm{~mm}$ from the apex using a double diamond blade (KG Sorensen, Barueri, SP, Brazil) in low speed (Kavo, Joinville, SC, Brazil). They were centred into polyvinyl chloride cylindrical moulds $(10 \mathrm{~mm}$ high by $16.7 \mathrm{~mm}$ inner diameter) with apexes fixed at the bottom of the cylinders in dental wax and embedded in polyester resin (Maxi Rubber Ind. Química Ltda, Diadema, SP, Brazil). During the embedding procedure, a \#25 K-file was kept within the canal to ensure a parallel position of the roots to mould walls. After the polyester resin had completely set, the specimens were removed from the moulds and longitudinally sectioned using a cutting machine (Isomet 1000; Buehler, Lake Bluff, IL, USA) with a diamond blade at $350 \mathrm{rpm}$ and water coolant, to obtain slices of the apical dentin $3 \mathrm{~mm}$ short from the apex and $2 \mathrm{~mm}$ thick.

Slices were positioned on a dental surveyor (B2 Delineator; Bio Art, São Carlos, SP, Brazil) using a specifically designed metallic sample holder to support the samples (Fig. 1). The canals were enlarged using a diamond conical drill \#701 (1.0 and $0.9 \mathrm{~mm}$ diameter at the base and at $2 \mathrm{~mm}$ below it, respectively) connected to a low speed handpiece (Dabi Atlante, Ribeirão Preto, SP, Brazil), which was kept attached to the arm of the dental surveyor to restrain lateral movements and keep drill-specimen 
alignment. The drill was introduced into root canal lumen up to the alignment of the coronal surface of the sample with the tip-end aiming to produce standardized cavities. The specimens were immersed and ultrasonically agitated in 17\% EDTA for $3 \mathrm{~min}$, washed with saline, dried with paper points (Dentsply-Herpo, Petropolis, RJ, Brazil) and randomly distributed in groups $(n=7)$ according to the material used to fill the cavities (MTA, ZOE or Biodentine). Tested materials were mixed following the manufacturers' instructions and inserted in the cavities of the samples using hand condensers. Samples were placed over a glass slab covered by polyester film during the filling procedure and then stored at $37{ }^{\circ} \mathrm{C}$ and $95 \%$ humidity for 7 days. After this period, the samples' surfaces were lightly polished with \#600 grit silicon carbide sandpaper (Norton, Lorena, $\mathrm{SP}, \mathrm{Brazil})$ to remove sealer excess and then submitted to push-out testing.

Push-out bond strength was performed using an Emic DL 2000 testing machine (Emic) with a load cell of $1 \mathrm{kN}$ operating at a constant speed of $0.5 \mathrm{~mm} / \mathrm{min}$ and stainless steel cylindrical punch with an $0.8 \mathrm{~mm}$ diameter. The metallic device used to hold the sample during preparation was also employed to keep the sample in position throughout the test. Constant load was applied up to cement displacement. The maximum load was recorded in Newton (N) and then converted to Megapascal (MPa) using the following formula: $\mathrm{MPa}=\mathrm{N} / \mathrm{A}$; where, $\mathrm{N}=$ maximum load $(\mathrm{N}), A=$ bonding surface area $\left(\mathrm{mm}^{2}\right)$. The bonding surface area of each sample was calculated as: $\left(\pi r_{1}+\pi r_{2}\right)$ $x L$, where $L=\sqrt{ }\left(r_{1}-r_{2}\right)^{2}+h^{2} ; p$ is the constant $3.14, r_{1}$ and $r_{2}$ are the smaller and larger radii of the trunk conical preparation, respectively, and $h$ is the thickness of each section in $\mathrm{mm}$ measured with a digital caliper (Mitutoyo, Suzano, SP, Brazil).

After push-out testing, the samples were split in two halves to expose dentin walls in order to evaluate failure mode. A stereomicroscope (Tecnival SQF-F) with $35 x$ magnification was used and failure mode was classified as adhesive (when dentin walls were devoid of sealer), cohesive (when sealer's remains were observed on dentin walls) or mixed (with both patterns of failure).

\section{Statistical Analysis}

Data from setting time, flow ability, radiopacity, $\mathrm{pH}$, compressive strength and bond strength were submitted to ANOVA and Tukey post-hoc test. Failure mode data were analysed by Kruskall-Wallis and Dunn's test. All statistical tests were performed with 5\% significance.

\section{Results}

Mean and standard deviations obtained with tested materials in the different assays are in Table 1. Biodentine exhibited the shortest initial and final setting time and the lowest radiopacity values $(p<0.05)$. Biodentine and MTA exhibited similar compressive strength values after $24 \mathrm{~h}$ ( $\mathrm{p}>0.05)$. However, Biodentine displayed statistically superior compressive strength values in comparison to MTA after 21 days ( $p>0.05$ ). ZOE presented the lowest compressive strength values for both periods of evaluation ( $24 \mathrm{~h}$ and 21 days) $(p<0.05)$.

The $\mathrm{pH}$ produced by the materials in the storage solution is in Table 2. The peak of alkalinisation was detected 7 days after mixing MTA and Biodentine $(p>0.05)$. In the subsequent periods (14 and 21 days), there was a slight decrease in $\mathrm{pH}$ values, with Biodentine still presenting higher $\mathrm{pH}$ values in comparison to MTA $(p<0.05)$. ZOE cement demonstrated minimum influence on $\mathrm{pH}$, exhibiting values close to neutral levels throughout
Figure 1. Metallic sample holder used to support the samples during root canal enlargement (A); higher magnification of the highlighted area (white square) on "Fig. 1A" (B); Sample before (C) and after (D) root canal preparation. 
the experiment.

Biodentine showed greater bond strength values than MTA $(p<0.05)$ (Table 1). There was no statistical difference among cements as regards the failure modes $(p>0.05)$. Most failures were adhesive (Fig. 2).

\section{Discussion}

Biodentine is considered a potential material to replace MTA, since the latter has been related to some negative clinical effects such as tooth discoloration (10). The performance of Biodentine on root-end cavities as retrofilling material has already been reported in clinical studies with positive outcomes (5). However, the real advantages of using Biodentine as retrograde filling material is still undisclosed. Thus, this study was designed to compare the physicochemical properties and bond strength of these materials to the apical third of the radicular dentin. ZOE cement was used as control since it had demonstrated similar clinical effectiveness to MTA in randomized clinical trials (11).

The investigation of material's physicochemical properties is important to foresee their clinical behavior. In this study, Biodentine was able to set faster than MTA and ZOE cement and this is possibly related to the addition of calcium chloride in the liquid vehicle that acts as setting accelerator (3). The accelerating effect of calcium chloride on MTA and Portland cement has been reported in the dental literature (12). This finding is important, taking into consideration that retrograde fillings are performed in surgical settings and cements will be immediately exposed to bleeding; blood contamination may interfere on bond strength values of MTA and Biodentine as root-end filling materials (13). Thus, a fast setting of the retrograde material is desired to produce a stable apical sealing.

The radiopacifier in Biodentine was shown to be zirconium oxide (3). In this study, Biodentine exhibited radiopacity values lower than $3 \mathrm{mmAl}$, which is the minimum value established by the ISO 6876:2012 standard (9). The radiopacity values observed with Biodentine corroborate the findings of Tanalp et al. who also observed values inferior to $3 \mathrm{mmAl}$ (14). However, some investigations observed radiopacity values superior to $3 \mathrm{mmAl}$ (7). This difference among studies may be related to the settings used to take the $\mathrm{X}$-ray images, such as $m A, k V$, time of exposure and distance between $\mathrm{X}$-ray source and samples, or even associated to the image acquisition, if it was obtained using conventional occlusal films or digital sensors. Thus, variations on radiopacity data are expected.

In this experiment, cylinders with $6 \mathrm{~mm}$ diameter and 12 $\mathrm{mm}$ high were used to keep a height to diameter ratio of 2 and,

*Different letters in the same column indicate statistically significant differences $(p<0.05)$.
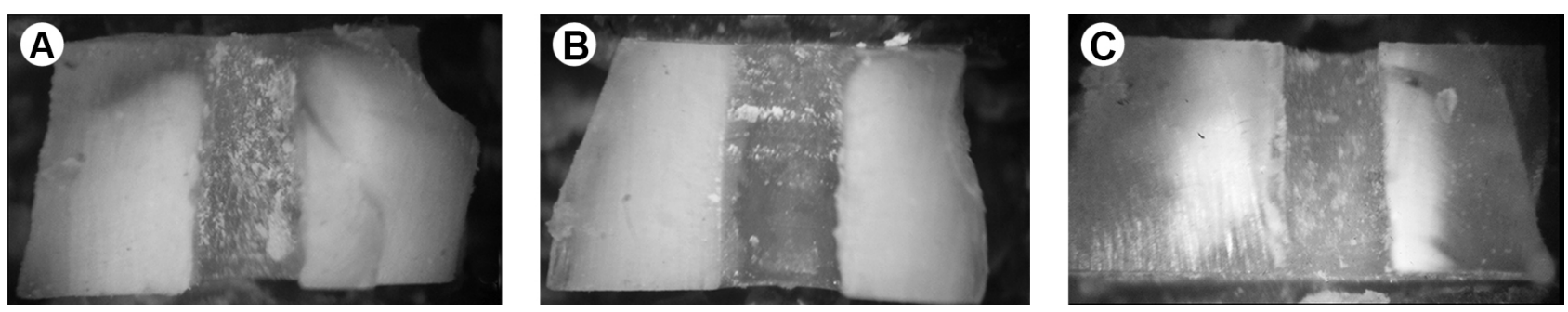

Figure 2. Predominant failure mode (adhesive) observed on stereomicroscope (35× magnification) of Biodentine (A), ZOE (C) and MTA (C). 
consequently, to avoid restraining effects of the loading plates. Ratio values higher than 2 may lead to buckling of the specimens and lower values require the use of a correction factor when calculating the compressive strength (15). According to the results, Biodentine exhibited higher compressive strength than MTA after 21 days storage. The addition of polycarboxylate-based hydrosoluble polymers in the liquid of the cement explain this result since it acts as water reducing agent and allows low water/powder ratio. Therefore, the resulting structure of the material has lower porosity and, consequently, higher compressive strength.

The ability to alkalinize the medium exhibited by calcium silicate-based cements relates to the hydration ability displayed by these material when they interact with water producing calcium silicate hydrate (C-S-H) and calcium hydroxide (Portlandite). The dissociation of calcium hydroxide increases $\mathrm{pH}$, besides providing calcium ions to the medium (16). Both MTA and Biodentine exhibited ability to alkalize the medium in the first week, when the peak of alkalinization was detected and, after this a slight decrease in $\mathrm{pH}$ was observed, with Biodentine still presenting higher values compared with MTA. As expected, ZOE cement had a minor influence on $\mathrm{pH}$, showing values close to neutral in all evaluation periods.

Push-out testing has been widely accepted to evaluate dentin bond strength of root canal sealers, since it assesses dentin bond strength in conditions comparable to clinical situations. The dentin bond strength evaluation used in the present study was based on Nunes et al. (17), which also used root dentin slices with the canal space enlarged by conic diamond drill. With the purpose of assessing the bond strength of root-end filling materials to the apical dentin, Marques et al. (18) proposed a new methodology using ultrasound tips to prepare the root-end cavities. Different from this study, the root canal space of the apical dentin was enlarged using diamond drills instead of ultrasound tips aiming to produce root-end cavities with standardized dimensions and to avoid the influence of other variables on bond strength values, such as ultrasound intensity, inclination of the tip during preparation and homogeneous grinding of the dentin walls. This is a very important aspect considering that cement's bond strength is calculated based on the area of contact between cements and dentin. Thus, the drill was kept attached to the harms of a dental surveyor throughout preparation to restrain lateral movements. Nevertheless, the use of diamond drills to prepare the cavities produces rough dentin surfaces. Another option would be the use of diamond-coated ultrasound tips (19). This has to be considered, since surface roughness may have increased the material's micromechanical retention and bond strength.

Some studies suggested that the resistance of
Biodentine to dislodgment improves with time (8). In this study, samples were submitted to push-out test 7 days after placing tested materials in the root canal space to allow the complete maturation of the cements. It is also important to note that the push-out data observed in this study are not to be compared to studies where the dislodgment resistance of the evaluated materials was tested in furcal perforations, since dentin tubule orientation may influence the bonding effectiveness (20).

All cements tested in this study are suitable for rootend filling and what differentiates one material from the others is the ability to provide a stable apical seal. Ideally, a retrograde filling material should not only to provide a tight seal of the apical third of roots submitted to apicectomy and root-end preparations. However, it should adhere to dentin and resist to dislodgment to assure apical sealing stability, taking into consideration that calcium silicate-based cements are also used to perform apical barriers in traumatized teeth that usually require prosthetic rehabilitation and intracanal reinforcement to increase their resistance to fracture (21). Therefore, these materials should resist to dislodgement when occlusal forces are indirectly applied. The dentin bond strength exhibited by Biodentine and MTA has already been compared in other studies in different conditions. In general, Biodentine presented greater resistance to dislodgment than MTA regardless the intracanal dressing, irrigating solution and environment acidity (22-24). Corroborating these findings, Biodentine has also demonstrated, in this study, superior adhesion to apical dentin compared to MTA. This observation may be related to material's furnished system of Biodentine (capsule system), which results in a homogeneous mixture and minimizes the effect that some aspects, such as water/powder ratio, temperature, humidity, quantity of air trapped in the mixture, and particle size, may have on the retention of the calcium silicate-based cements to the dentin walls (25).

Regardless the similar application of Biodentine and MTA in Endodontics, the results of the present study indicate that Biodentine might perform clinically better as retrograde material due to the improved physicochemical properties and bond strength. It may be concluded that Biodentine exhibited faster setting, higher long-term compressive strength and bond strength to the apical dentin than MTA and ZOE.

\section{Resumo}

0 objetivo deste estudo foi avaliar as propriedades físico-químicas e a resistência de união à dentina apical do cimento Biodentine em comparação ao MTA branco e cimento à base de óxido de zinco e eugenol (OZE). 0 tempo de presa e a radiopacidade foram avaliados de acordo com as especificações ISO 6876:2012. 0 tempo de presa final, a resistência à compressão e o $\mathrm{pH}$ também foram avaliados. A resistência 
de união dos materiais à dentina apical do canal radicular foi avaliada por meio do ensaio push-out. Dados foram analisados por ANOVA e teste complementar de Tukey-Krammer. Biodentine apresentou o menor tempo de presa inicial $(16,2 \pm 1,48 \mathrm{~min})$ e final $(35,4 \pm 5,55 \mathrm{~min})$. Os valores de radiopacidade do Biodentine $(2,79 \pm 0,27 \mathrm{mmAl})$ não estão de acordo com as especificações ISO 6876:2012. Por outro lado, este material apresentou maior resistência à compressão após 21 dias $(37,22 \pm 5,27 \mathrm{MPa})$ e maiores valores de adesão à dentina $(11,2 \pm 2,16 \mathrm{MPa})$ em comparação ao MTA branco $(27,68 \pm 3,56 \mathrm{MPa}$ de resistência à compressão e 2,98 $\pm 0,64 \mathrm{MPa}$ de resistência de união) ( $p>0.05)$. Ambos os materiais produziram ambiente alcalino (aproximadamente 10) ( $p>0.05$ ) em comparação ao OZE ( $\mathrm{pH} 7$ ). Pode-se concluir que o Biodentine demonstrou endurecimento mais rápido e apresentou maior resistência à compressão e resistência de união à dentina apical do que MTA e OZE.

\section{References}

1. Danesh F, Tootian Z, Jahanbani J, Rabiee M, Fazelipour S, Taghva 0 , et al.. Biocompatibility and mineralization activity of fresh or set white mineral trioxide aggregate, biomimetic carbonated apatite, and synthetic hydroxyapatite. J Endod 2010;36:1036-1041.

2. Camilleri J, Kralj P, Veber M, Sinagra E. Characterization and analyses of acid-extractable and leached trace elements in dental cements. Int Endod J 2012;45:737-743.

3. Camilleri J, Sorrentino F, Damidot D. Investigation of the hydration and bioactivity of radiopacified tricalcium silicate cement, Biodentine and MTA Angelus. Dent Mater 2013;29:580-593.

4. http://www.septodont.co.uk/sites/default/files/ brochureBiodentineHDUK.pdf - accessed in October 2016.

5. Pawar AM, Kokate SR, Shah RA. Management of a large periapical lesion using Biodentine ${ }^{\mathrm{T} M}$ ) as retrograde restoration with eighteen months evident follow up. J Conserv Dent 2013;16:573-575.

6. Nielsen MJ, Casey JA, VanderWeele RA, Vandewalle KS. Mechanical properties of new dental pulp-capping materials. Gen Dent. 2016;64:44-48.

7. Grech $L$, Mallia B, Camilleri J. Investigation of the physical properties of tricalcium silicate cement-based root-end filling materials. Dent Mater 2012;29:20-28.

8. Aggarwal V, Singla M, Miglani S, Kohli S. Comparative evaluation of push-out bond strength of ProRoot MTA, Biodentine, and MTA Plus in furcation perforation repair. J Conserv Dent 2013;16:462-465.

9. International Organization for Standardization Dentistry - Root Canal Sealing Materials. London, UK: British Standards Institution ISO 6876:2012.

10. Marciano MA, Duarte MA, Camilleri J. Dental discoloration caused by bismuth oxide in MTA in the presence of sodium hypochlorite. Clin Oral Investig 2015;19:2201-2209.

11. Lindeboom JA, Frenken JW, Kroon FH, van den Akker HP. A comparative prospective randomized clinical study of MTA and IRM as root-end filling materials in single-rooted teeth in endodontic surgery. Oral Surg Oral Med Oral Pathol Oral Radiol Endod 2005;100:495-500.
12. Bortoluzzi EA, Broon NJ, Bramante CM, Felippe WT, Tanomaru Filho M, Esberard RM. The influence of calcium chloride on the setting time, solubility, disintegration, and $\mathrm{pH}$ of mineral trioxide aggregate and white Portland cement with a radiopacifier. J Endod 2009;35:550-554.

13. Akcay H, Arslan H, Akcay M, Mese M, Sahin NN. Evaluation of the bond strength of root-end placed mineral trioxide aggregate and Biodentine in the absence/presence of blood contamination. Eur J Dent 2016;10:370-375.

14. Tanalp J, Karapınar-Kazandağ M, Dölekoğlu S, Kayahan MB. Comparison of the radiopacities of different root-end filling and repair materials. Scientific World Journal 2013;23:594950.

15. Camilleri J, Montesin FE, Curtis RV, Ford TR. Characterization of Portland cement for use as a dental restorative material. Dent Mater 2006;22:569-575.

16. Sarkar NK, Caicedo R, Ritwik P, Moiseyeva R, Kawashima I. Physicochemical basis of the biologic properties of mineral trioxide aggregate. J Endod 2005;31:97-100.

17. Nunes VH, Silva RG, Alfredo $E$, Sousa-Neto MD, Silva-Sousa YT. Adhesion of Epiphany and AH Plus sealers to human root dentin treated with different solutions. Braz Dent J 2008;19:46-50

18. Marques JH, Silva-Sousa YT, Rached-Júnior FJ, Mazzi-Chaves JF, Miranda CE, da Silva SR, et al. New methodology to evaluate bond strength of root-end filling materials. Braz Dent J 2015;26:288-291.

19. Zuolo ML, Perin FR, Ferreira MO, de Faria FP. Ultrasonic root-end preparation with smooth and diamond-coated tips. Endod Dent Traumatol 1999;15:265-268

20. Montagner AF, Carvalho MP, Susin AH. Microshear bonding effectiveness of different dentin regions. Indian J Dent Res 2015;26:131-135.

21. Sivieri-Araujo G, Tanomaru-Filho M, Guerreiro-Tanomaru JM, Bortoluzzi EA, Jorge ÉG, Reis JM. Fracture resistance of simulated immature teeth after different intra-radicular treatments. Braz Dent J 2015;26:211-215.

22. Nagas E, Cehreli ZC, Uyanik MO, Vallittu PK, Lassila LV. Effect of several intracanal medicaments on the push-out bond strength of ProRoot MTA and Biodentine. Int Endod J 2016;49:184-188

23. Guneser MB, Akbulut MB, Eldeniz AU. Effect of various endodontic irrigants on the push-out bond strength of biodentine and conventional root perforation repair materials. J Endod 2013;39:380384.

24. Elnaghy AM. Influence of acidic environment on properties of biodentine and white mineral trioxide aggregate: a comparative study. J Endod 2014;40:953-957.

25. Torabinejad $M$, Watson TF, Pitt Ford TR. Sealing ability of a mineral trioxide aggregate when used as a root end filling material. J Endod 1993;19:591-595.
Received June 14, 2016

Accepted November 30, 2016 